\title{
The Role of Medical Interpretation on Breast and Cervical Cancer Screening Among Asian American and Pacific Islander Women
}

\author{
Jeff Dang • Jessica Lee • Jacqueline H. Tran • Marjorie Kagawa-Singer • \\ Mary Anne Foo • Tu-Uyen N. Nguyen • Annalyn Valdez-Dadia • Jasmin Thomson • \\ Sora Park Tanjasiri
}

Published online: 30 March 2010

(C) The Author(s) 2010. This article is published with open access at Springerlink.com

\begin{abstract}
We examined whether the impact of medical interpretation services was associated with the receipt of a mammogram, clinical breast exam, and Pap smear. We conducted a large cross-sectional study involving four Asian American and Pacific Islander (AAPI) communities with high proportions of individuals with limited English proficiency (LEP). Participants were recruited from community clinics, churches and temples, supermarkets, and other community gathering sites in Northern and Southern California. Among those that responded, $98 \%$ completed the survey rendering a total of 1,708 AAPI women. In a series of multivariate logistic regression models, it was found that women who typically used a medical interpreter had a greater odds of having
\end{abstract}

J. Dang $(\bowtie) \cdot$ J. Lee $\cdot$ J. Thomson

Consulting Measurement Group, Inc,

2390 Crenshaw Blvd. \#110,

Torrance, CA 90501, USA

e-mail: jdang@webcmg.com

J. H. Tran • M. A. Foo

Orange County Asian and Pacific

Islander Community Alliance (OCAPICA),

12900 Garden Grove Blvd., Suite 214A,

Garden Grove, CA 92843, USA

M. Kagawa-Singer $\cdot$ A. Valdez-Dadia

UCLA School of Public Health and Department

of Asian American Studies,

650 Charles Young Drive South, PO Box 951772,

LA, CA 90095-1772, USA

T.-U. N. Nguyen

Asian American Studies Program, California State University Fullerton, 800 North State College Blvd.,

Fullerton, CA 92831, USA

S. P. Tanjasiri

Department of Health Science, California State University Fullerton, 800 North State College Blvd.,

Fullerton, CA 92831, USA received a mammogram (odds ratio $[\mathrm{OR}]=1.85 ; 95 \%$ confidence interval $[\mathrm{CI}]=1.21,2.83)$, clinical breast exam $(\mathrm{OR}=$ 3.03; $95 \% \mathrm{CI}=1.82,5.03)$, and a Pap smear $(\mathrm{OR}=2.34 ; 95 \%$ $\mathrm{CI}=1.38,3.97)$ than those who did not usually use an interpreter. The study provides support for increasing language access in healthcare settings. In particular, medical interpreters may help increase the utilization of breast and cervical cancer screening among LEP AAPI women.

Keywords Medical interpretation - Breast cancer - Cervical cancer-Screening $\cdot$ Asian American · Pacific Islander women

\section{Introduction}

Asian Americans and Pacific Islanders (AAPIs) are some of the fastest growing minority groups in the USA, with California home to the largest numbers of AAPIs (4.8 million) in the country. For all AAPIs, cancer constitutes the leading cause of death [1], with breast cancer the leading site for cancer incidence and mortality for AAPI women [2]. Compared with all other racial groups, Pacific Islanders in California possess the second highest age-adjusted mortality (33.4 per 100,000) for breast cancer [3]. With regards to cervical cancer, incidence rates among Southeast Asian women are three times higher than non-Hispanic white women in the USA [4]. These figures provide support for increased attention to breast and cervical cancer among AAPI women. However, there is limited research available regarding Cambodian, Laotian, Thai, and Tongan communities.

\section{Language Access}

The AAPI population has been characterized as "linguistically isolated" based on estimates indicating that, out of all racial groups, they have the highest percentage (34\%) of 
individuals aged 14 years or older who speak English less than "very well" [5]. These language barriers have been shown to challenge their ability to seek healthcare $[6,7]$. In particular, studies have shown that limited English proficiency (LEP) can negatively influence healthcare utilization and subsequently result in adverse outcomes. Language barriers play an enormous role in determining patientphysician trust, quality, and accuracy of medical care [712]. In addition to the hindered communication, AAPI LEP individuals have been found to have lower income, less formal education, and poor insurance status, all of which have been linked to decreased visits to the physician $[7,11$, 13]. Cultural differences may significantly impact medical beliefs and practices. For instance, Western-trained healthcare providers might disregard Asian or Eastern medicine when treating patients due to cultural differences. Compounded with the fact that many LEP individuals are unfamiliar with the American health system, miscommunication may often occur between patients and providers, leading to unsatisfied or confused patients and potential health risks $[6,7,11,14,15]$. According to the US Department of Health and Human Services, language access standards for LEP patients include ensuring language assistance services such as medical interpreters and translated patient-related documents in health care settings [16]. Unfortunately, medical interpreters are rarely available to LEP patients. A survey of 86 public and private hospitals found that approximately $11 \%$ of all patients are in need of interpretive services [17]. Despite the demand, however, it has been estimated that less than $25 \%$ of hospitals provide medical interpretation training for their staff and less than $11 \%$ provide training for their volunteers [17]. With a limited number of trained medical interpreters available in medical care settings, patients are likely to receive no medical interpretation or to communicate through ad hoc interpreters such as family members or friends [18]. Using untrained interpreters can increase the risk of errors in translation, such as omission, addition, condensation, and substitution, which can have detrimental health and legal consequences, including misdiagnosis, inaccurate treatment, and failure to follow-up on appointments [19-22]. Finally, it has also been shown that LEP patients who are not provided with interpretive services and rely on ad hoc interpreters are less satisfied with their health care interactions and have worse health-related outcomes compared with patients who use trained medical interpreters [23].

\section{Breast and Cervical Cancer Screening}

AAPI women, in aggregate, exhibit lower rates than other ethnic groups in receiving mammograms and Pap smears, which are vital in early cancer detection and treatment. This lower rate of screening partly contributes to growing trends in breast and cervical cancer mortality for AAPI women [12, 24]. Reasons for such low screening rates include reports of dissatisfaction with healthcare experiences, economic burden, being uncomfortable with physician/staff members, distrust of medical procedures, inability to understand treatment/prescription instructions, cultural taboos associated with "feminine problems," and lack of knowledge regarding Western medical "culture" and practices [18]. A common contributing factor in all of these issues is the lack of language access in healthcare settings $[6,7,12,15,21$, 25]. To further examine the link between language access and health utilization, the present study evaluates whether medical interpretation is associated with prior receipt of mammograms, clinical breast exams (CBE), and Pap smears among four groups of AAPI women (Cambodians, Laotians, Thais, and Tongans). It was hypothesized that those who reported regular use of medical interpretation would have greater odds of having received both breast and cervical cancer screenings.

\section{Methods}

\section{Measures}

The PATH for Women ("Promoting Access to Health for Pacific Islander and Southeast Asian Women") project planning team (including principal investigator, project staff, and evaluation consultants) developed baseline survey questions that evaluated the following: (1) demographic characteristics for each community, (2) healthcare access indicators (e.g., insurance status, location of medical care, gender, and ethnicity of doctor), (3) language access (whether or not the participant ever wanted or requested an interpreter), and (4) breast and cervical cancer knowledge, attitudes, beliefs, and behaviors. Several of the survey questions were extracted from existing standardized questionnaires including the National Health Interview Survey and the California Health Interview Survey. A completed draft of the survey was reviewed by the PATH for Women partners for relevance, comprehensiveness, applicability, and validity. Any discrepancies or issues of wording were discussed and resolved to produce a final survey of 93 questions [26].

\section{Sample}

The PATH for Women study was undertaken to investigate and help eliminate the problem of low breast and cervical cancer screenings in several AAPI communities. In order to reach these underserved ethnic populations, a sampling plan was developed to capture all the important demographic characteristics of the Cambodian, Laotian, Thai, and 
Tongan communities. Participants were recruited from various community clinics, churches and temples, supermarkets, and other community gathering sites in Northern and Southern California between 2002 and 2003. Sites in Northern California included Sacramento, San Francisco, San Mateo, Alameda, Contra Costa, Monterey, Santa Clara, Sutter County, Solano, and San Jose Counties and Southern California sites primarily included Los Angeles and Orange Counties. Eligible participants included Cambodian, Laotian, Thai, and Tongan foreign-born women who fell under four major demographic spectra: age (35 years and older), socioeconomic status (high, medium, and low), language capacity (non-English speaking, bilingual, English only), and income (defined differently within each community; [26]). Of those contacted by the interviewers, 98\% completed the survey. Respondents were compensated with grocery gift certificates equivalent to 20 dollars for their participation.

The study protocol was approved by the University of California, Los Angeles (UCLA) Human Subjects Institutional Review Board (IRB; No. G02-07-107-01), and verbal consent was provided by all of the participants. Bilingual community health workers who were trained in survey administration and completed UCLA's online IRB training conducted face-to-face interviews in the language most preferred by the participant. The survey questions were translated by bilingual study interviewers into Cambodian, Laotian, Thai, and Tongan and reviewed by community advisory communities for accuracy and discrepancies. The translated survey drafts were also reviewed by bilingual community-based staff members in each survey administration site to ensure equal applicability across the geographic areas [26]. Culturally tailored prompts were developed to help interviewers provide clear, accurate, and understandable descriptions of all medical concepts and terminology contained in the survey.

A total of 1,825 individuals were interviewed, but 117 surveys were excluded from the analysis. Medical interpretation served as the primary grouping variable, so participants who did not provide a response for this grouping variable were excluded $(n=117)$. The final sample included 1,708 foreignborn Cambodians $(n=344)$, Laotians $(n=353)$, Thais $(n=725)$, and Tongans $(n=286)$.

\section{Variables}

Respondents were asked if they had ever received a mammogram, clinical breast exam, and Pap smear in their lifetime. Dichotomous responses on these three questions served as dependent variables in the multivariate analyses. The regular receipt of medical interpretive services served as the primary grouping variable. As part of a series of questions pertaining to their regular medical provider, participants were asked, "Who usually interprets for you?" The responses were initially coded into ten categories but then collapsed into four for analysis: (1) "None" indicating no one usually provided interpretation, (2) "Family or friends" including a child family member, an adult family member, or friend, (3) "Bilingual staff" including a staff member at the medical site or a bilingual staff member at the medical site, and (4) "Medical interpreters" including professional medical interpreter paid for by the client, professional medical interpreter paid for by the doctor or hospital, or telephone language line. If the participant did not have a regular provider, then the subsequent questions including the one pertaining to interpretive services were relative to their most recent visit.

Sociodemographic and additional language access variables were included in the analyses as potential confounders. Sociodemographic variables included age in years, years living in the USA, level of education, employment status, ability to pay for necessities, ethnicity, marital status, and medical insurance status. Language access variables included the language that the participant preferred to speak during their visits and exposure to information regarding breast and cervical cancer. For the language preference variable, respondents were asked, "What language do you prefer to speak to your doctor or medical provider?" Responses were dichotomized into two, those who preferred to speak English and those who did not. Finally, participants were asked, "In the past two years, what sources of information for breast and cervical cancer have you been exposed to?" Responses were grouped into four categories: (1) health education sources (such as educational brochures or pamphlets and community outreach workers), (2) mass media outlets (such newspapers, radio, and television), (3) family/friends, and (4) health providers.

\section{Data Analysis}

Data were entered, cross-checked, and analyzed in SPSS 14.0. One-way analysis of variance (ANOVA) and chisquare statistics were conducted to compare the four medical interpretation groups on relevant sociodemographic variables. Cohen's effect size estimate $d$ was calculated for all ANOVAs and $w$ for all chi-square statistics [27]. For descriptive purposes, $d=0.20,0.50$, and 0.80 and $w=0.10$, 0.30 , and 0.50 were defined as small, medium, and large effect sizes, respectively.

Missing data were excluded for bivariate analyses. However, prior to multivariate analysis, an imputation procedure for missing data replacement was conducted for the missing points using the software program NORM. According to Cole [28], missing data are usually dealt with by either deleting all cases with missing data from an analysis (i.e., casewise or pairwise deletion) or by replacing 
all missing values for a variable with the variable's mean. However, each of these approaches suffers from practical and theoretical problems. In particular, casewise and pairwise deletion can lead to the loss of statistical power while mean replacement shrinks the variance of a variable and can lead to more significant group differences as well as attenuated correlations [29]. Therefore, a process called Bayesian imputation $[30,31]$ was used for the current study. Bayesian imputation is a process that imputes values that preserve the covariance matrix and mean vector of the data, including a degree of random error that matches the observed data. With large databases, one will often extract several databases from the multiple imputation process and run analyses on all of the data bases; however, Rubin and Schenker [32] have demonstrated that a single-step (i.e., one database) Bayesian imputation works well in most cases with clinical data.

All pertinent independent and dependent variables within the database that had less than $30 \%$ missing were imputed to replace missing values. Language preference, use of interpretive services, source of health information, insurance status, and questions regarding breast and cervical cancer screenings were subject to imputation. Those variables with more than $30 \%$ of the data missing were considered too many to impute and were therefore excluded from the study.

A systematic check for all statistical assumptions was conducted prior to analysis. Descriptive statistics were examined for both continuous and categorical variables including means, standard deviations (SD), minimum and maximum values, and skewness and kurtosis $z$-scores were reviewed. For categorical data, frequency and percentage values were reviewed for each variable. The data were also checked for multicollinearity.

Descriptive statistics were also run on all pertinent variables in the model to review general distributions. Multivariate logistic regressions were performed to examine the influence of language ability and interpretive services on receipt of a mammogram, clinical breast exam, and Pap smear in their lifetime after controlling for relevant confounding variables. Subsequently, the odds ratios and confidence intervals were evaluated for significant effects. To examine whether the geographic location of the survey had an impact on the results, sensitivity analysis was performed including site as a covariate. This variable was found to be nonsignificant and excluded from the model.

\section{Results}

Participants were categorized into four groups based on who usually provided language interpretation during their medical visits: "none" $(n=757,44.3 \%)$, "family or friends"
( $n=380,22.2 \%)$, "bilingual staff" $(n=351,20.5 \%)$, and "medical interpreter" $(n=220,12.9 \%)$. Sociodemographic characteristics were compared across the four groups, and the corresponding results are provided in Table 1. Significant differences were found on all of the sociodemographic variables, but the largest effects were found on age, education, and ethnicity.

The mean age of the sample was $49.9(\mathrm{SD}=11.6)$. Those who used a medical interpreter and family or friends were on average about 3 years older than those who used bilingual staff and 6 years older than those who did not use interpreters. In addition, years in the USA was associated with the language interpretation categories. Approximately $25 \%(n=172)$ of those who resided in the USA between $0-10$ years $(n=402)$ had reported not using an interpreter. Most participants in the sample had reported living in the USA between 11 to 20 years $(n=712,42.3 \%)$. Of this group, approximately $40 \%$ had reported not using an interpreter $(n=282)$. Finally, among the AAPI women in the sample with over 20 years residency in the USA $(n=570)$, approximately $52 \%$ has reported not using an interpreter $(n=294)$.

Education varied across the groups. Approximately $31.9 \%$ of those in the none group had gone to college, university, or vocational school, whereas only $6 \%$ of those in the family or friends, $3.2 \%$ of those in the bilingual staff, and $2 \%$ of those in the medical interpreter groups had received a similar level of education. About half of the sample had difficulty paying for necessities and were unemployed at the time of the interview while more than half of sample were married and had some form of medical insurance. The Thais were the largest AAPI group represented in the sample, followed by Laotians, Cambodians, and Tongans. Medical interpreters had been frequently used by $47.7 \%$ of Cambodians, but this was less common in the other groups: $27.7 \%$ for Laotians, $23.6 \%$ for Thais, and $0.9 \%$ for Tongans.

Table 2 provides frequencies and percentages for the language access variables across the four groups. Three fourths of the sample preferred to speak a non-English language with their medical provider, and this proportion varied significantly across the groups. A large proportion of those in the bilingual staff $(94.3 \%)$, medical interpreter $(93.6 \%)$, and family or friends $(88.9 \%)$ groups preferred to speak non-English with their doctor or medical provider. Furthermore, over half (54\%) of those who preferred to speak a non-English language with their doctor or medical provider did not use any type of interpretation. In the total sample, there was a high rate of exposure to information about breast and cervical cancer from family/friends (57.7\%), but only $39.3 \%$ had received cancer-related information from mass media outlets; $36.5 \%$ received information from health education sour- 
Table 1 Sociodemographic characteristics of survey participants, $n(\%)$

\begin{tabular}{|c|c|c|c|c|c|c|c|c|}
\hline Variable & $\begin{array}{l}\text { None } \\
(n=757)\end{array}$ & $\begin{array}{l}\text { Family or } \\
\text { friends } \\
(n=380)\end{array}$ & $\begin{array}{l}\text { Bilingual } \\
\text { staff } \\
(n=351)\end{array}$ & $\begin{array}{l}\text { Medical } \\
\text { interpreter } \\
(n=220)\end{array}$ & $\begin{array}{l}\text { Total sample } \\
(n=1,708)\end{array}$ & Statistic & $\begin{array}{l}p \\
\text { value }\end{array}$ & $\begin{array}{l}\text { Effect } \\
\text { size } \\
\text { statistic }\end{array}$ \\
\hline Age in years, mean $(\mathrm{SD})$ & $46.8(9.8)$ & $53.4(13.8)$ & $50.9(10.6)$ & $53.1(11.8)$ & $49.9(11.6)$ & $F=37.60$ & $<0.001$ & $d=0.52$ \\
\hline \multicolumn{9}{|l|}{ Years in the USA, $n(\%)$} \\
\hline $\begin{array}{l}0 \text { to } 10 \text { years } \\
11 \text { to } 20 \text { years }\end{array}$ & $\begin{array}{l}172(23.0) \\
282(37.7)\end{array}$ & $\begin{array}{r}95(25.5) \\
158(42.5)\end{array}$ & $\begin{array}{r}96(27.7) \\
148(42.8)\end{array}$ & $\begin{array}{r}39(17.9) \\
124(56.9)\end{array}$ & $\begin{array}{l}402(23.9) \\
712(42.3)\end{array}$ & \multirow[t]{2}{*}{$\chi^{2}=34.53$} & \multirow[t]{2}{*}{$<0.001$} & \multirow[t]{2}{*}{$w=0.14$} \\
\hline Over 20 years & $294(39.3)$ & $119(32.0)$ & $102(29.5)$ & $55(25.2)$ & $570(33.8)$ & & & \\
\hline \multicolumn{9}{|l|}{ Education, $n(\%)$} \\
\hline $\begin{array}{l}\text { None } \\
\text { Elementary to high school }\end{array}$ & $\begin{array}{r}105(17.4) \\
90(15.0)\end{array}$ & $\begin{array}{r}116(34.8) \\
34(10.2)\end{array}$ & $\begin{array}{c}176(51.5) \\
13(3.8)\end{array}$ & $\begin{array}{l}64(31.7) \\
12(5.9)\end{array}$ & $\begin{array}{l}461(31.2) \\
149(10.1)\end{array}$ & \multirow[t]{4}{*}{$\chi^{2}=326.83$} & \multirow[t]{4}{*}{$<0.001$} & \multirow[t]{4}{*}{$w=0.47$} \\
\hline College/university/vocational & $192(31.9)$ & $20(6.0)$ & $11(3.2)$ & $4(2.0)$ & $227(15.3)$ & & & \\
\hline ESL/adult school & $176(29.2)$ & $143(42.9)$ & $129(37.7)$ & $107(53.0)$ & $555(37.5)$ & & & \\
\hline Unknown & $39(6.5)$ & $20(6.0)$ & $13(3.8)$ & $15(7.4)$ & $87(5.9)$ & & & \\
\hline \multicolumn{9}{|l|}{ Employment, $n(\%)$} \\
\hline $\begin{array}{l}\text { Yes } \\
\text { No }\end{array}$ & $\begin{array}{l}451(59.7) \\
304(40.3)\end{array}$ & $\begin{array}{l}158(42.0) \\
218(58.0)\end{array}$ & $\begin{array}{l}174(49.9) \\
175(50.1)\end{array}$ & $\begin{array}{r}68(31.8) \\
146(68.2)\end{array}$ & $\begin{array}{l}843(49.8) \\
851(50.2)\end{array}$ & $\chi^{2}=66.59$ & $<0.001$ & $w=0.20$ \\
\hline \multicolumn{9}{|c|}{ Ability to pay for necessities, $n(\%)$} \\
\hline $\begin{array}{l}\text { Not difficult } \\
\text { Difficult }\end{array}$ & $\begin{array}{l}478(65.2) \\
255(34.8)\end{array}$ & $\begin{array}{l}147(39.8) \\
222(60.2)\end{array}$ & $\begin{array}{l}116(33.7) \\
228(66.3)\end{array}$ & $\begin{array}{r}67(31.3) \\
147(68.7)\end{array}$ & $\begin{array}{l}808(48.7) \\
852(51.3)\end{array}$ & $\chi^{2}=148.40$ & $<0.001$ & $w=0.30$ \\
\hline \multicolumn{9}{|l|}{ Insurance, $n(\%)$} \\
\hline $\begin{array}{l}\text { Yes } \\
\text { No }\end{array}$ & $\begin{array}{l}509(67.2) \\
248(32.8)\end{array}$ & $\begin{array}{l}258(67.9) \\
122(32.1)\end{array}$ & $\begin{array}{l}192(54.7) \\
159(45.3)\end{array}$ & $\begin{array}{r}174(79.1) \\
46(20.9)\end{array}$ & $\begin{array}{r}1,133(66.3) \\
575(33.7)\end{array}$ & $\chi^{2}=38.00$ & $<0.001$ & $w=0.15$ \\
\hline \multicolumn{9}{|l|}{ Ethnicity, $n(\%)$ variable } \\
\hline $\begin{array}{l}\text { Cambodian } \\
\text { Laotian }\end{array}$ & $\begin{array}{r}112(14.8) \\
82(10.8)\end{array}$ & $\begin{array}{r}48(12.6) \\
112(29.5)\end{array}$ & $\begin{array}{l}79(22.5) \\
98(27.9)\end{array}$ & $\begin{array}{r}105(47.7) \\
61(27.7)\end{array}$ & $\begin{array}{l}344(20.1) \\
353(20.7)\end{array}$ & \multirow[t]{3}{*}{$\chi^{2}=347.92$} & \multirow[t]{3}{*}{$<0.001$} & \multirow[t]{3}{*}{$w=0.45$} \\
\hline Thai & $346(45.7)$ & $154(40.5)$ & $173(49.3)$ & $52(23.6)$ & $725(42.4)$ & & & \\
\hline Tongan & $217(28.7)$ & $66(17.4)$ & $1(0.3)$ & $2(0.9)$ & $286(16.7)$ & & & \\
\hline \multicolumn{9}{|l|}{ Marital status, $n(\%)$} \\
\hline $\begin{array}{l}\text { Unmarried } \\
\text { Married }\end{array}$ & $\begin{array}{l}248(32.8) \\
484(64.0)\end{array}$ & $\begin{array}{l}130(34.4) \\
226(59.8)\end{array}$ & $\begin{array}{l}152(43.4) \\
173(49.4)\end{array}$ & $\begin{array}{r}86(39.1) \\
122(55.5)\end{array}$ & $\begin{array}{r}616(36.2) \\
1,005(59.0)\end{array}$ & \multirow[t]{2}{*}{$\chi^{2}=26.53$} & \multirow[t]{2}{*}{$<0.001$} & \multirow[t]{2}{*}{$w=0.13$} \\
\hline Living as married & $24(3.2)$ & $22(5.8)$ & $25(7.1)$ & $12(5.5)$ & $83(4.9)$ & & & \\
\hline
\end{tabular}

ces $(36.5 \%)$ and $18.4 \%$ from health providers. Those who used medical interpreters were the least likely to have received breast and cervical cancer information from health education sources $(26.4 \%)$, mass media outlets (29.1\%), and family/friends (52.7\%) than any other group, and differences on these variables were statistically significant but small in magnitude.

Table 3 provides frequencies and percentages for health utilization grouped by use of interpretive services. In the total sample, $55.7 \%, 68.9 \%$, and $72.8 \%$ had reported the receipt of a mammogram, CBE, and Pap smear, respectively. Those who used medical interpreters had the highest percentage of mammograms (66.8\%) and CBEs (82.3\%) compared with the other groups (none, $49.9 \%, 62.1 \%$; family or friends, $55.8 \%$, $63.2 \%$; bilingual staff, $62.1 \%, 81.5 \%$ ). Those who used bilingual staff members had the highest rate of Pap smears (85.8\%) compared with the other groups (none, $65.1 \%$; family or friends, $77.1 \%$; medical interpreters, $81.8 \%$ ).
To further determine the importance of interpreters in accessing screening services after controlling for relevant confounding variables, multivariate logistic regression models were run (see Table 4). Age, years living in the USA, ethnicity, language preference, source of information on cancer, and medical interpretation services were significant predictors of mammograms. Years living in the USA, education, ethnicity, marital status, insurance status, source of information on breast and cervical cancer, and medical interpretation were significant predictors of CBEs. Age, years living in the USA, ethnicity, marital status, insurance status, language preference, source of information on breast and cervical cancer, and medical interpretation were significant predictors of Pap smears. Separate analyses revealed that those who used medical interpreters had 1.85 greater odds of a mammogram, 3.03 greater odds of a CBE, and 2.34 greater odds of a Pap smear than those who did not use any type of interpreter after controlling for other 
Table 2 Language access characteristics of survey participants, $n(\%)$

$\begin{array}{lllllll}\begin{array}{l}\text { None } \\ (n=757)\end{array} & \begin{array}{l}\text { Family or friends } \\ (n=380)\end{array} & \begin{array}{l}\text { Bilingual staff } \\ (n=351)\end{array} & \begin{array}{l}\text { Medical } \\ \text { interpreter } \\ (n=220)\end{array} & \begin{array}{l}\text { Total sample } \\ (n=1,708)\end{array} & \text { Statistic } & \begin{array}{l}p \\ \text { value }\end{array}\end{array}$

Preferred language to speak to doctor or medical provider

\begin{tabular}{|c|c|c|c|c|c|c|c|c|}
\hline English & $348(46.0)$ & $42(11.1)$ & $20(5.7)$ & $14(6.4)$ & $424(24.8)$ & \multirow[t]{2}{*}{$\chi^{2}=328.99$} & \multirow[t]{2}{*}{$<0.001$} & \multirow[t]{2}{*}{$w=0.44$} \\
\hline Non-English & $409(54.0)$ & $338(88.9)$ & $331(94.3)$ & $206(93.6)$ & $1,284(75.2)$ & & & \\
\hline \multicolumn{9}{|c|}{ Source of information on breast and cervical cancer } \\
\hline \multicolumn{9}{|c|}{ Health education } \\
\hline Yes & $273(36.1)$ & $143(37.6)$ & $149(42.5)$ & $58(26.4)$ & $623(36.5)$ & \multirow[t]{2}{*}{$\chi^{2}=15.39$} & \multirow[t]{2}{*}{0.002} & \multirow[t]{2}{*}{$w=0.10$} \\
\hline No & $484(63.9)$ & $237(62.4)$ & $202(57.5)$ & $162(73.6)$ & $1,085(63.5)$ & & & \\
\hline \multicolumn{9}{|l|}{ Mass media } \\
\hline Yes & $336(44.4)$ & $128(33.7)$ & $143(40.7)$ & $64(29.1)$ & $671(39.3)$ & \multirow[t]{2}{*}{$\chi^{2}=23.15$} & \multirow[t]{2}{*}{$<0.001$} & \multirow[t]{2}{*}{$w=0.12$} \\
\hline No & $421(55.6)$ & $252(66.3)$ & $208(59.3)$ & $156(70.9)$ & $1,037(60.7)$ & & & \\
\hline \multicolumn{9}{|c|}{ Family and friends } \\
\hline Yes & $466(61.6)$ & $214(56.3)$ & $189(53.8)$ & $116(52.7)$ & $985(57.7)$ & \multirow[t]{2}{*}{$\chi^{2}=9.28$} & \multirow[t]{2}{*}{0.026} & \multirow[t]{2}{*}{$w=0.07$} \\
\hline No & $291(38.4)$ & $166(43.7)$ & $162(46.2)$ & $104(47.3)$ & $723(42.3)$ & & & \\
\hline \multicolumn{9}{|c|}{ Health providers } \\
\hline Yes & $144(19.0)$ & $66(17.4)$ & $60(17.1)$ & $45(20.5)$ & $315(18.4)$ & \multirow[t]{2}{*}{$\chi^{2}=1.48$} & \multirow[t]{2}{*}{0.688} & \multirow[t]{2}{*}{$w=0.03$} \\
\hline No & $613(81.0)$ & $314(82.6)$ & $291(82.9)$ & $175(79.5)$ & $1,393(81.6)$ & & & \\
\hline
\end{tabular}

variables in the model. Furthermore, those who used bilingual staff members for interpretation had 2.23 greater odds of a CBE and 2.82 greater odds of a Pap smear than those who did not report using any type of interpretation. However, bilingual staff members did not have significantly greater odds of having received a mammogram than those who did not report using any type of interpretation. Finally, those who had used family or friends for interpretation were not found to have greater odds of having received breast and cervical cancer screenings after accounting for other variables in the model.

\section{Discussion}

From our study, AAPI women clearly face enormous barriers to health care due to language. Although there is a growing body of literature on medical interpretation, existing studies have focused mainly on Spanish-speaking populations, and few studies have included LEP women from the AAPI community. To our knowledge, this study represents the largest sample of AAPI women in the medical interpretation literature. Our investigation found that $75.2 \%$ of the AAPI women sampled preferred to speak a language other than English with their doctor or medical provider. Among these women $(n=752), 31.8 \%$ did not use any kind of interpretation and $44.9 \%$ used ad hoc interpreters such as family and friends. Therefore, over three fourths of AAPI women who prefer to speak nonEnglish with their provider did not regularly communicate using a bilingual staff member or a medical interpreter.

The national health promotion and disease prevention objectives, under Healthy People 2010, has established a specific target for increasing the proportion of women aged

Table 3 Health utilization grouped by use of interpretive services, $n(\%)$

\begin{tabular}{|c|c|c|c|c|c|c|c|c|}
\hline & $\begin{array}{l}\text { None } \\
(n=757)\end{array}$ & $\begin{array}{l}\text { Family or friends } \\
(n=380)\end{array}$ & $\begin{array}{l}\text { Bilingual staff } \\
(n=351)\end{array}$ & $\begin{array}{l}\text { Medical interpreter } \\
(n=220)\end{array}$ & $\begin{array}{l}\text { Total sample } \\
(n=1708)\end{array}$ & Statistic & $\begin{array}{l}p \\
\text { value }\end{array}$ & $\begin{array}{l}\text { Effect size } \\
\text { statistic }\end{array}$ \\
\hline \multicolumn{9}{|c|}{ Mammogram } \\
\hline No & $383(50.6)$ & $168(44.2)$ & $133(37.9)$ & $73(33.2)$ & $757(44.3)$ & \multirow[t]{2}{*}{$\chi^{2}=29.02$} & \multirow[t]{2}{*}{$<0.001$} & \multirow[t]{2}{*}{$w=0.13$} \\
\hline Yes & $374(49.4)$ & $212(55.8)$ & $218(62.1)$ & $147(66.8)$ & $9,951(55.7)$ & & & \\
\hline \multicolumn{9}{|c|}{ Clinical breast examination (CBE) } \\
\hline No & $287(37.9)$ & $140(36.8)$ & $65(18.5)$ & $39(17.7)$ & $531(31.1)$ & \multirow[t]{2}{*}{$\chi^{2}=66.55$} & \multirow[t]{2}{*}{$<0.001$} & \multirow[t]{2}{*}{$w=0.20$} \\
\hline Yes & $470(62.1)$ & $240(63.2)$ & $286(81.5)$ & $181(82.3)$ & $1,177(68.9)$ & & & \\
\hline \multicolumn{9}{|c|}{ Pap smear } \\
\hline No & $264(34.9)$ & $110(28.9)$ & $50(14.2)$ & $40(18.2)$ & $464(27.2)$ & \multirow[t]{2}{*}{$\chi^{2}=61.94$} & \multirow[t]{2}{*}{$<0.001$} & \multirow[t]{2}{*}{$w=0.19$} \\
\hline Yes & $493(65.1)$ & $270(71.1)$ & $301(85.8)$ & $180(81.8)$ & $1,244(72.8)$ & & & \\
\hline
\end{tabular}


Table 4 Logistic regression of sociodemographic and language access characteristics on receipt of screening

\begin{tabular}{|c|c|c|c|c|c|c|}
\hline & \multicolumn{2}{|c|}{ Mammogram } & \multicolumn{2}{|c|}{ Clinical breast examination (CBE) } & \multicolumn{2}{|l|}{ Pap smear } \\
\hline & Odds ratio & $95 \% \mathrm{CI}$ & Odds ratio & $95 \% \mathrm{CI}$ & Odds ratio & $95 \% \mathrm{CI}$ \\
\hline \multicolumn{7}{|l|}{ Demographics } \\
\hline Age & 1.06 & $1.05,1.08$ & 1.00 & $0.99,1.02$ & 0.98 & $0.97,1.00$ \\
\hline \multicolumn{7}{|l|}{ Years in the USA } \\
\hline 0 to 10 years & 1.00 & - & 1.00 & - & 1.00 & - \\
\hline 11 to 20 years & 3.23 & $2.30,4.52$ & 1.65 & $1.13,2.43$ & 1.98 & $1.30,3.04$ \\
\hline Over 21 years & 3.41 & $2.31,5.03$ & 2.00 & $1.30,3.10$ & 2.50 & $1.55,4.05$ \\
\hline Employment & 1.38 & $1.29,1.89$ & 1.12 & $0.80,1.57$ & 1.44 & $0.98,2.11$ \\
\hline Ability to pay for necessities & 1.07 & $0.83,1.43$ & 0.94 & $0.67,1.31$ & 0.76 & $0.52,1.10$ \\
\hline \multicolumn{7}{|l|}{ Education } \\
\hline None & 1.00 & - & 1.00 & - & 1.00 & - \\
\hline Elementary to high school & 0.72 & $0.44,1.18$ & 1.74 & $1.02,2.98$ & 1.60 & $0.86,2.95$ \\
\hline College/university/vocational & 1.05 & $0.66,1.68$ & 1.65 & $0.94,2.88$ & 0.94 & $0.51,1.73$ \\
\hline ESL/adult school & 1.38 & $1.00,1.88$ & 1.41 & $0.98,2.00$ & 1.28 & $0.87,1.88$ \\
\hline Unknown & 1.50 & $0.84,2.69$ & 2.84 & $1.31,6.16$ & 1.34 & $0.64,2.98$ \\
\hline \multicolumn{7}{|l|}{ Ethnicity } \\
\hline Cambodian & 1.00 & - & 1.00 & - & 1.00 & - \\
\hline Laotian & 1.32 & $0.91,1.94$ & 2.05 & $1.30,3.14$ & 1.84 & $1.15,2.94$ \\
\hline Thai & 3.98 & $2.60,6.10$ & 6.55 & $4.04,10.60$ & 4.45 & $2.64,7.70$ \\
\hline Tongan & 0.40 & $0.23,0.72$ & 0.29 & $0.16,0.51$ & 0.08 & $0.04,0.16$ \\
\hline \multicolumn{7}{|l|}{ Marital status } \\
\hline Unmarried & 1.00 & - & 1.00 & - & 1.00 & - \\
\hline Married & 1.21 & $0.92,1.58$ & 1.73 & $1.27,2.34$ & 1.85 & $1.32,2.60$ \\
\hline Living as married & 1.17 & $0.66,2.05$ & 2.00 & $0.96,4.19$ & 1.74 & $0.78,3.90$ \\
\hline \multicolumn{7}{|l|}{ Do you have insurance? } \\
\hline No & 1.00 & - & 1.00 & - & 1.00 & - \\
\hline Yes & 1.23 & $0.90,1.68$ & 1.62 & $1.14,2.30$ & 1.50 & $1.00,2.23$ \\
\hline \multicolumn{7}{|l|}{ Language access } \\
\hline \multicolumn{7}{|c|}{ Language preference in medical setting } \\
\hline English & 1.00 & - & 1.00 & - & 1.00 & - \\
\hline Non-English & 0.46 & $0.31,0.70$ & 0.59 & $0.38,0.92$ & 0.40 & $0.23,0.69$ \\
\hline \multicolumn{7}{|l|}{ Interpretive services } \\
\hline No one & 1.00 & - & 1.00 & - & 1.00 & - \\
\hline Family or friends & 1.25 & $0.87,1.77$ & 0.89 & $0.60,1.29$ & 1.44 & $0.93,2.22$ \\
\hline Bilingual staff members & 1.35 & $0.95,1.92$ & 2.23 & $1.47,3.40$ & 2.82 & $1.75,4.55$ \\
\hline Medical interpreters & 1.85 & $1.21,2.83$ & 3.03 & $1.82,5.03$ & 2.34 & $1.38,3.97$ \\
\hline \multicolumn{7}{|c|}{ Source of information on breast and cervical cancer } \\
\hline \multicolumn{7}{|l|}{ Information: health education } \\
\hline No & 1.00 & - & 1.00 & - & 1.00 & - \\
\hline Yes & 1.40 & $1.08,1.82$ & 1.41 & $1.04,1.91$ & 1.33 & $0.95,1.89$ \\
\hline \multicolumn{7}{|l|}{ Information: mass media } \\
\hline No & 1.00 & - & 1.00 & - & 1.00 & - \\
\hline Yes & 0.95 & $0.74,1.24$ & 0.81 & $0.60,1.08$ & 1.19 & $0.85,1.67$ \\
\hline \multicolumn{7}{|l|}{ Information: family/friends } \\
\hline No & 1.00 & - & 1.00 & - & 1.00 & - \\
\hline Yes & 0.79 & $0.61,1.02$ & 0.90 & $0.70,1.21$ & 0.98 & $0.71,1.35$ \\
\hline
\end{tabular}


Table 4 (continued)

\begin{tabular}{|c|c|c|c|c|c|c|}
\hline & \multicolumn{2}{|c|}{ Mammogram } & \multicolumn{2}{|c|}{ Clinical breast examination (CBE) } & \multicolumn{2}{|l|}{ Pap smear } \\
\hline & Odds ratio & $95 \% \mathrm{CI}$ & Odds ratio & $95 \% \mathrm{CI}$ & Odds ratio & $95 \% \mathrm{CI}$ \\
\hline \multicolumn{7}{|c|}{ Information: healthcare providers } \\
\hline No & 1.00 & - & 1.00 & - & 1.00 & - \\
\hline Yes & 1.43 & $1.03,1.98$ & 1.71 & $1.12,2.61$ & 2.30 & $1.37,3.87$ \\
\hline
\end{tabular}

Significant values are in italics $(p<0.05)$

40 years and older who have received a mammogram within the preceding 2 years from $60 \%$ to $70 \%$ and increasing the proportion of women 18 years and older who have ever had a Pap test from $85 \%$ to $97 \%$ [24]. In the current sample, the proportion of those who had received a mammogram, CBE, and Pap smear was 55.7\%, 68.9\%, and $72.8 \%$, respectively, rates which fall far below the national objectives. The results also indicated that women utilizing medical interpreters were between two to three times greater odds of screening than those who did not. The regular use of bilingual staff members to provide interpretation services was also associated with greater breast and cervical cancer screening among AAPI women. The differences between using medical interpreters versus bilingual staff on patient satisfaction and medical outcomes requires further investigation, including issues related to costeffectiveness and staff efficiency.

We must note that there are limitations to the study. While the overall sample size is strong, this study only represents a convenience sampling of women in the targeted communities and may not be generalizable to other AAPI communities. The study data, as well, is crosssectional and limits our examination of screening behavior to one point in time and does not allow us to examine the influence of language and interpretive services on cancer screening. It is important to note that the results of this study do not conclude a causal relationship between the use of medical interpreters and cancer screening rates. The survey design and translation are also issues which may limit the generalizability and comparability of findings. While particular questions were taken from standardized surveys, such as the National Health Interview Survey and the California Health Interview Survey, some of the questions could not be asked verbatim because they may have been considered inappropriate. For example, one of the survey questions asked if survey respondents "were employed last week." However, our community partners discussed how this was a very invasive and insensitive question which should not be translated literally. Rather, they suggested that we translate the question and phrase it as "what where you doing last week" and pose answer options in correlation with employment. In this manner, our community partners felt the question was more sensitive and would elicit honest responses without creating pressures about the need to be employed by community members. In addition, the cognitive equivalence of some questions occasionally required changing the wording for the interview to make them more understandable to the respondent. Therefore, in cases where the literal translation would have expressed a different meaning than intended, questions and answer options were discussed to assure a meaningful translation was conveyed. Lastly, in asking our questions about professional medical interpretation services, we did not specify a definition for a trained professional interpreter, nor did we evaluate the levels of training that the medical interpreter had; therefore, respondents may have had a different understanding of what was meant by the term "professional" and possibly used an interpreter with difficulty understanding medical terms. To account for this, "professional medical interpreters" were more broadly categorized as "medical interpreters." The survey also did not identify whether the healthcare provider spoke their native language and whether the screening service occurred in this country or in their country of origin. In addition, although the current study presents the use of interpretive services in conjunction with English proficiency, equivalency is not assumed between these two variables.

Future studies should devote attention to these issues, as well as assessing the economic costs and benefits for interpretive services on breast and cervical cancer screening outcomes (including follow-up care and treatment). A regular repeated screening as an outcome variable to understand factors related to long-term screening adherence would add knowledge about AAPI medical implication. Additional research could focus on the last recent visit with the HCP and the language and interpreter, as well as a closer look at a closed system of care (i.e., one medical setting or HMO or randomized trial of types of interpreters). In addition, there are several other factors that could be evaluated as predictors of cancer screening behavior among SEA and PI women including knowledge, attitudes, and beliefs regarding screening, physician recommendations, 
and culturally specific customs. They should also be strongly considered for future research.

The importance of language access in healthcare settings has been a growing issue. Title VI of the Civil Rights Act of 1964 stipulated that "no person in the United States shall, on the ground of race, color, or national origin, be excluded from participation in, be denied benefits of, or be subjected to discrimination under any program or activity receiving federal financial assistance" [33]. In accordance with this Act, many hospitals are obligated to provide interpretive services to linguistically isolated patients $[12$, 22]. While this is the mandate, few hospitals and medical providers provide language access services (such as trained interpreters) for their patients.

AAPI women are severely underrepresented in language access research [13, 15, 34, 35]. Considering the increasing prevalence of breast and cervical cancer among this population, we believe it is crucial for health care organizations to provide language access services to promote early detection and decrease mortality. Our study adds to the limited, but growing literature on breast and cervical cancer screening among underserved AAPI subpopulations $[6,7,15,20,24,25,34,36,37]$. Formally training bilingual medical providers along with other important ancillary staff (including bilingual and bicultural patient navigators) should be an important component for programs that aim to reduce cancer and other health disparities for LEP AAPI and other medically underserved communities.

Open Access This article is distributed under the terms of the Creative Commons Attribution Noncommercial License which permits any noncommercial use, distribution, and reproduction in any medium, provided the original author(s) and source are credited.

\section{References}

1. Wingo PA, Ries LA, Rosenberg HM, Miller DS, Edwards BK (1998) Cancer incidence and mortality, 1973-1995: a report card for the U.S. Cancer 82(6):1197-1207

2. Jenkins C, Kagawa-Singer M (1994) Cancer. In: Zane N, Takeuchi D, KNJ Y (eds) Confronting critical health issues of Asian and Pacific Islander Americans. Sage Publications, Thousand Oaks, pp 105-147

3. CDHS (2004) Sentinel health indicators for California's multicultural populations, 1999-2001. California Department of Heatlh Services, Center for Health Statistics, Office of Health Information and Research, Sacramento

4. Taylor V, Jackson J, Schwartz S, Tu S, Thompson B (1996) Cervical cancer among Asian American women: a neglected public health problem? Asian Am Pac Isl J Health 4(4):327-342

5. Census of the Population SF 4 (2000). US Census Bureau, Washington, DC, United States.
6. Ngo-Metzger Q, Massagli MP, Clarridge BR et al (2003) Linguistic and cultural barriers to care. J Gen Intern Med 18:44-52

7. Ngo-Metzger Q, Massagli MP, Clarridge BR et al (2000) Patientcentered quality measures for Asian Americans: research in progress. Am J Med Qual 15(4):167-173

8. Ponce NA, Hays RD, Cunningham W (2006) Linguistic disparities in health care access and health stats among older adults. J Gen Intern Med 21:786-791

9. Tanjasiri SP, Tran J, Kagawa-Singer M et al (2004) Exploring access to cancer control services for Asian-American and Pacific Islander communities in Southern California. Ethn Dis 14 (Supplemental 1):S1-14-S11-19

10. Nguyen T-UN, Kagawa-Singer M, Tanjasiri SP, Foo MA (2003) Vietnamese American women's health: a community's perspective and report. Amerasia J 29(1):183-197

11. Woloshin S, Schwartz LM, Katz SJ, Welch HG (1997) Is language a barrier to the use of preventive services? J Gen Intern Med 12:472-477

12. Andrulis D, Goodman N, Pryor C (2002) What a difference an interpreter can make: health care experiences of uninsured with limited English proficiency. The Access Project, Boston

13. Ashing-Giwa KT, Padilla GV, Tejero JS, Kim J (2004) Breast cancer survivorship in a multiethnic sample: challenges in recruitment and measurement. Cancer 101:450-465

14. Tanjasiri SP, Kagawa-Singer M, Nguyen T-UN, Foo MA (2002) Collaborative research as an essential component for addressing cancer disparities among Southeast Asian and Pacific Islander women. Health Promot Pract 3(2):144-154

15. Snyder RE, Cunningham W, Nakazono TT, Hays RD (2000) Access to medical care reported by Asians and Pacific Islanders in a West Coast physician group association. Med Care Res Rev 57 (2):196-215

16. Services USDoHaH (2001) National standards for culturally and linguistically appropriate services in health care. In: U.S. Bureau of Health and Human Services OoMH, ed

17. Ginsberg C, Martin D, Andrulis D, Shaw-Taylor Y, McGregor C (1995) Interpretation and translation services in health care: a survey of US public and private teaching hospitals. National Public Health and Hospital Institute, Washington, DC

18. Groups SSG (2001) Needs assessment report on the breast and cervical cancer screening needs and recommendations for Cambodians, Chamorros, Laotians, Samoans, Thais, Tongans, and Vietnamese. Special Services for Group, Inc, Los Angeles, CA

19. Dower C (2003) Health care interpreters in California. UCSF Center for the Health Professions, San Francisco

20. Flores G, Laws MB, Mayo SJ et al (2003) Errors in medical interpretation and their potential clinical consequences in pediatric encounters. Pediatrics 111:6-14

21. Carrasquillo O, Orav JE, Brennan TA, Burstin HR (1999) Impact of language barriers on patient satisfaction in an emergency department. J Gen Intern Med 14:82-87

22. Jacobs EA, Lauderdale DS, Meltzer D, Shorey JM, Levinson W, Thisted RA (2001) Impact of interpreter services on delivery of health care to limited-English-proficient patients. J Gen Intern Med 16:468-474

23. Flores $G$ (2005) The impact of medical interpreter service on the quality of health care: a systematic review. Med Care Res Rev 62 (3):255-299

24. Kagawa-Singer M, Pourat N (2000) Asian American and Pacific Islander breast and cervical carcinoma screening rates and Healthy People 2000 Objectives. Cancer 89:696-705

25. Rivadeneyra R, Elderkin-Thompson V, Silver RC, Waitzkin H (2000) Patient centeredness in medical encounters requiring an interpreter. Am J Med 108:470-474

26. Kagawa-Singer M, Tanjasiri SP, Lee SW et al (2006) Breast and cervical cancer control among Pacific Islander and Southeast 
Asian women: participatory action research strategies for baseline data collection in California. J Cancer Educ 21(Suppl):S53-S60

27. Cohen J (1988) Statistical power analysis for the behavioral sciences. Lawrence Erlbaum, Hillsdale, NJ

28. Cole JC (2007) How to deal with missing data: conceptual overview and details for implementing two modern methods. In: Osborne JW (ed) Best practices in quantitative methods. Sage, Thousand Oaks, CA, pp 214-238

29. Schafer JL, Olsen M (1998) Multiple imputation for multivariate missing data problems: a data analyst's perspective. Multivariate Behav Res 33:545-571

30. Rubin DB (1976) Inference and missing data. Biometrika 63:581-592

31. Rubin DB (1996) Multiple imputation after 18+ years. J Am Stat Assoc 91(434):473-489

32. Rubin DB, Schenker N (1991) Multiple imputation in healthcare databases: an overview and some applications. Stat Med 10:585-598
33. Title VI of the Civil Rights Act of 1964: Policy guidance on the prohibition against national origin discrimination as it affects persons with limited English proficiency. In: Services DoHaH (ed). Washington, DC: Office for Civil Rights; 2002

34. Li CI, Malone KE, Daling JR (2003) Differences in breast cancer stage, treatment, and survival by race and ethnicity. Arch Intern Med 163:49-56

35. Tanjasiri SP, Sablan-Santos L (2001) Breast cancer screening among Chamorro women in Southern California. J Women's Health Gend-Based Med 10(5):479-485

36. Jacobs EA, Karavalos K, Rathouz PJ, Ferris TG, Powell LH (2005) Limited English proficiency and breast and cervical cancer screening in a multiethnic population. Am J Public Health 95 (8):1410-1416

37. Hiatt RA, Pasick RJ, Stewart S et al (2001) Community-based cancer screening for underserved women: design and baseline findings from the breast and cervical cancer intervention study. Prev Med 33:190-203 